\section{A STUDY OF CONSUMER BEHAVIOUR TOWARDS AIR FILLED POTATO CHIPS PACKET IN ASSAM, INDIA.}

KEY WORDS: Potato chips

Consumer behavior, brand

loyalty, buying behavior.

\title{
Aditee Mitra*
}

Student, Gauhati Commerce College, Gauhati University, Guwahati, Assam, India. * Corresponding Author

Potato chips, one of the most enjoyed and popular snacks attract consumers of various age groups. While the truth is that the demand of potato chips is never ending, what is interesting here is that even though consumers are dissatisfied due to excess air content in potato chips, still they prefer to have it from time to time. It is unusual to find such buying behavior of consumers. This paper aims to highlight in depth about the factors that cause such behavior and also throw light towards the brand loyalty of such consumers.

INTRODUCTION Potato chips are one of the most popular snacks of today's generation. With most people consuming potato chips, one might wonder what attracts consumers even though most of them consist of proportionately higher air content. This particular behavior of consumers is very important to understand not just from marketing point of view but also for further use of this information by various interested parties. In today's world, it has become increasingly important to understand such behavior of consumers. Every organization wants to win the heart of consumers and keep increasing its base. They leave no stone unturned in their attempt to know and do so. To know the consumer, understanding their buying behavior and accordingly making strategies related to it is one of the most crucial activities for any organization."Consumer behavior is the study of the process involved when individuals or groups select, purchase, use or dispose of product, services, ideas or experiences to satisfy needs and desires."(Solomon et al, 2006). Although maturing with each passing day, this field has gradually gained immense importance in the last decade and continues to do even so. Although there are various brands producing potato chips and each one differing in taste, price and other factors, people continue liking each one of them. However, what is not clear is the fact regarding the buying behavior of consumers towards proportionately higher air filled potato chips. In general, consumers never like to be fooled and immediately shift to other brand in case they feel cheated. Thus, this research is an attempt to understand and analyze the reasons behind this odd buying decision of consumers with regards to air filled potato chips packet. Another aspect is to study the brand loyalty of consumers towards air filled potato snacks packets and also highlight if they are ready to shift to a better product, both in quantity and quality with proportionately less air content.

\section{LITERATURE REVIEW}

C. Sundarapandi, M.Karthik\&A.K.Subramani (2015) in their study discussed about the customer satisfaction towards Lays chips in Avadi, Chennai. The research was conducted using convenience sampling technique and data collection was done through survey method. The study also revolved around the percentage of population who like to eat snacks, most preferred flavor of Lays and to analyze the reason for the popularity of their preferred snacks. The study concluded that most of the respondents would recommend Lays chips and age; gender or occupation had hardly any influence on factors related to customer satisfaction.

Gayatri Joshi \&RuchiraShukla (2012) in their study analyzed the preference in market for various packed snacks in South Gujarat. The focus of the study was also on consumer behavior regarding packed snacks and the perception of consumers towards various brands related to it. Data was collected through structured and non -disguised questionnaire and analysis was done through statistical tools like averages and percentages. The study highlighted that both-consumers from rural and urban region favored packed snacks. Certain factors that were responsible for such decision were availability, freshness, taste \& quantity. Another huge impacting factor was impulse buying. The study further suggested that better management of distribution network \& replacement of various packed snacks across most retails stores at regular intervals were needed.

Dr Manish Kumar \& Dr A.K. Tiwari (2014) in their study stressed on the factors that affect the consumers to buy Lays and attempt was also made to determine the role of advertising on buying behavior of consumers, to check the celebrity endorsement's effectiveness for the promotion of Lays and analyze the awareness source of consumers related to Lays. Data was collected through structured questionnaire and analyzed through descriptive statistical tools and SPSS statistical software. The study revealed that Lays was one of the most enjoyed snacks and quality and advertising played a great role in attracting consumers. As per the study, the consumers also stated that they preferred availability of product more than packaging or price and celebrities like Saif Ali Khan played a major role in influencing buying behavior of consumers.

HadiqaRiaz, Hassaan Ahmed, Dr SaimaAkhter, MudassirHussain (2017) in their study highlighted about the influence of emotional branding on customer's buying behavior, the role played by it in differentiating each brand from the competitors and factors related to emotional branding that influence buying behavior of customers. The study suggested that there exists a positive relationship between buying behavior and emotional branding \& it played a major role in attracting as well as retaining customers.

DavinaMadhaviChinnapen -Sathan, VanishaOogarah Hanuman \&RoomaRoshneeRamsaran- Fowdar (2012) in their study focused on the impact that advertising has played in attracting consumers in soft drink market of Coca Cola and how it affects consumer behavior. An attempt was further made to find the effectiveness of Coca Cola advertisements to identify consumers' perceptions towards such advertisement s. The study was made possible through collection of data through structured and undisguised questionnaire .SPSS software was used for analysis and descriptive and interferential analysis was done accordingly. The study highlighted the fact that although people were becoming more concerned about their health and it has indeed led to a reduced consumption but there is still a positive impact of advertising on the buying behavior of consumers.

Dean Martin C and Baby Joseph (2013) made an attempt to analyze and study the behavior of customers who bought ready to eat snacks and the perception that retailers had towards potato chips. The study identified that most 
consumers are inclined towards spicy flavored chips. As per their study, consumers believe that more can be given with the same price. Also, most people consume such snacks for time pass followed by taste factor. The study concluded that consumers prefer such snacks by giving preference to lower price as the most important factor followed by variety and availability of it.

N Ramya\& Dr. SA Mohamed Ali (2018) in their study focused on buying behavior of consumers towards products of AMUL with great focus on city of Coimbatore. For the study, questionnaire filled by respondents were used for primary data and analysis was done accordingly. Their study found that products of AMUL were consumed at a higher rate when compared to others. Infact, consumer behavior was found to be positive and products had a greater reach due to this. The study further suggested that promotional strategies should be improved to help in increasing sales.

E. Thangasamy\& Dr. GautamPatikar (2014) stressed in their study about factors which influenced about buying behavior of consumers. The study conducted was empirical in nature. Only primary data collected from 300 respondents were used for further analysis. The focus was on selected durable goods \& preference of brands in consumers. Their study concluded that most decision of consumers vary according to the decision of buying. Also, deliberation of buyer is involved more for expensive \& complex brands. Their study also suggested that opening of new outlets in Nagaland can make sure that consumers find more convenient and comfort while making a purchase decision.

R. Vijayalakshmi\& DR. T.R. Gurumoorthy (2019) in their study highlighted about buying behavior of consumers with reference to biscuits. Convenient sampling technique was used for the study. Their study concluded that biscuits had immense popularity in consumers due to taste and low price. Advertisements also play a greater role as many consumers end up asking for specific biscuits as shown in advertisement s. They suggested that due to greater competition, new products should be developed by confectionary companies.

N. Satheesh Kumar, S.P. KaruppasamumyPandian\& R. Murali (2013) in their study highlighted about brand loyalty of consumers towards beverages like Pepsi Co- with special attention to Tiruchirappalli district. For the study, convenient sampling was used \& $\mathrm{t}$ - test was used for further analysis .Their study concluded that loyalty dimensions not only helped to increase sales but also focused on the fact that customers themselves started becoming loyal towards a brand. As per their study, consumers have a positive outlook towards brand name, product quality. By enhancing more about loyalty dimensions, more consumers can be retained \& new ones attracted.

SayanIMukherjee, SouravChatterjee, Nilanjan Ray (2018) in their study highlighted on buying behavior of consumers by making an analysis between Parle\& Britannia. Primary data was collected through face to face interaction survey \& secondary data from various magazines, journals etc was used for the study. Their study concluded that more people purchase Britannia than Parle. Also, Parle's delivery of advertisement contents attracted more consumers \& Britannia was the most preferred due to factors like price and taste. The study also suggested that priority should be given on attracting children as consumers through advertisements \& combo packs with discounts would be great. Also, companies should adopt innovative packaging.

\section{RESEARCH GAP}

After a considerable literature review was done, it has been found by the researcher that previously no such attempt has been made to find and analyze the reasons regarding buying behavior of consumers towards air filled potato chips packet in the state of Assam. There is prior research that suggests that consumers pick their choice according to taste, price etc but no significant research has been done prior that highlights about consumer's buying behavior towards air filled potato chips and about brand loyalty of them towards it.

\section{OBJECTIVES}

The study revolves around the following major objectives:

- To study the buying behavior of consumers towards air filled potato chips packet.

- To study the brand loyalty of consumers towards air filled potato chips packet.

\section{HYPOTHESES}

$\mathbf{H}_{1}$ : There is no significant statistical difference between males and females in consumer buying behavior towards air filled potato chips packet.

$\mathbf{H}_{2}$ : There is no significant statistical difference between males and females in brand loyalty towards air filled potato chips packet.

\section{METHODOLOGY}

The research conducted is explanatory and descriptive in nature. Data has been collected through online questionnaire with the help of snowballing technique. For the study, respondents in the age group of 18-24, majority consisting of students were taken. 200 participants were in the sample. This particular age group has been selected for the study by the researcher as majority of the people of this age group are college going students who are inclined towards consumptio $n$ of potato chips. The study area is the state of Assam. Further, the analysis of data was made possible by the use of SPSS statistical software. Independent $t$ - tests was conducted to analyze the objectives of the study. For this purpose, null and alternative hypothesis has been chosen accordingly for analysis and interpretation.

\section{ANALYSIS \& INTERPREATATION}

Dealing with first objective

The results of the test for objective one are depicted here.

\section{TABLE 1 AND 2}

\begin{tabular}{|l|l|r|r|r|}
\hline \multirow{2}{*}{} & $\begin{array}{l}\text { gender of } \\
\text { respondent }\end{array}$ & $\mathrm{N}$ & Mean & \multicolumn{1}{c|}{$\begin{array}{c}\text { Std. } \\
\text { Deviation }\end{array}$} \\
\hline \multirow{2}{*}{$\begin{array}{l}\text { reason for } \\
\text { liking }\end{array}$} & Male & 103 & 1.36 & 0.815 \\
\cline { 2 - 5 } & Female & 145 & 1.21 & 0.696 \\
\hline $\begin{array}{l}\text { source of } \\
\text { information }\end{array}$ & Male & 103 & 2.16 & 1.194 \\
\cline { 2 - 5 } & Female & 145 & 2.02 & 1.205 \\
\hline \multirow{2}{*}{$\begin{array}{l}\text { satisfaction } \\
\text { level of } \\
\text { current } \\
\text { product }\end{array}$} & Male & 103 & 3.33 & 0.912 \\
\cline { 2 - 5 } $\begin{array}{l}\text { influence of } \\
\text { celebrity } \\
\text { endorseme } \\
\text { nt }\end{array}$ & Male & 103 & 3.07 & 0.855 \\
\cline { 2 - 5 } & Female & 145 & 3.56 & 0.716 \\
\hline
\end{tabular}

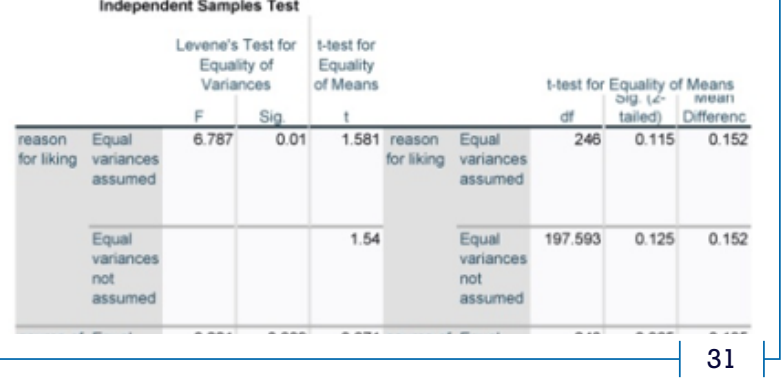




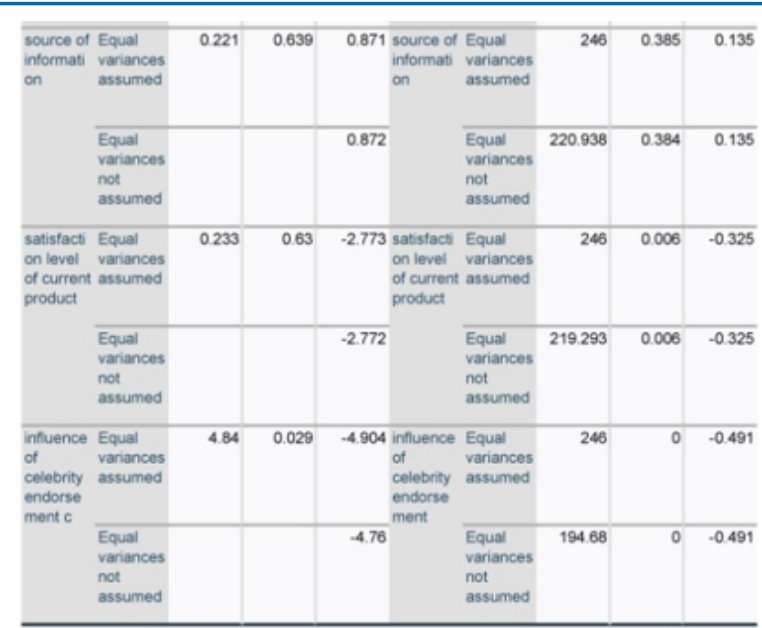

For the first objective, it is clearly indicated in the above tables that in first and second cases, null hypothesis has been accepted and in third and fourth cases, null hypothesis has been rejected. For the first and second case where the null hypothesis is accepted, it means that there is no significant statistical difference between males and females in consumer buying behavior towards air filled potato chips packet. In first case of reason of liking for potato chips, results between males and females are not statistically different. Thus, the outcome of the analysis shows not a significant statistical difference in their reason of liking towards potato chips for males where mean is 1.36 \& for females where mean is 1.21 . As the mean value of both groups is not much different, it means that both groups like potato chips of various brands for not very different reasons. Similarly in second case of source of information about knowing more flavors of potato chips, both males and females have no significant statistical difference in mean. Thus, the outcome of the analysis shows not a statistically difference in their mean values \& in case of males, it is $=2.16$ and of females $=2.02$. This signifies that both groups are inclined towards more or less towards the same source for getting information about more new flavors. For the third and fourth case where the null hypothesis is rejected, it means that there is a significant statistical difference between males and females in consumer buying behavior towards air filled potato chips packet. In the case of satisfaction level of using current product, it can be interpreted that in both males $\&$ females, there is a significant difference in mean. Thus, the statistically significant difference in mean can be explained as: for males where mean $=3.33 \&$ for females $=3.66$. The higher mean value of females signifies that females are more satisfied with the current usage of product when compared to males. Thus, this clearly tells us that both the groups are satisfied at different levels and females are more satisfied with their current usage of the product than males. Similarly, in case of celebrity endorsement, it can be interpreted that there is a significant statistical difference in the mean of the two groups. This difference can be explained as: mean for males $=3.07 \&$ for females $=3.56$. This higher mean value of females indicates that they are more influenced due to celebrity endorsement for buying potato chips when compared to males. Males tend to show lesser influence in this case.

\section{Dealing with the second objective:}

The results of the test for objective two are depicted here.

\section{TABLE 3}

Independent Samples Test

\begin{tabular}{c|c} 
Levene's Test for & $\begin{array}{c}\text { t-test for } \\
\text { Equality of } \\
\text { Equality of Variances }\end{array}$ \\
Means
\end{tabular}

Sig. $\quad t \quad$ df $\quad$ tailed) Difference

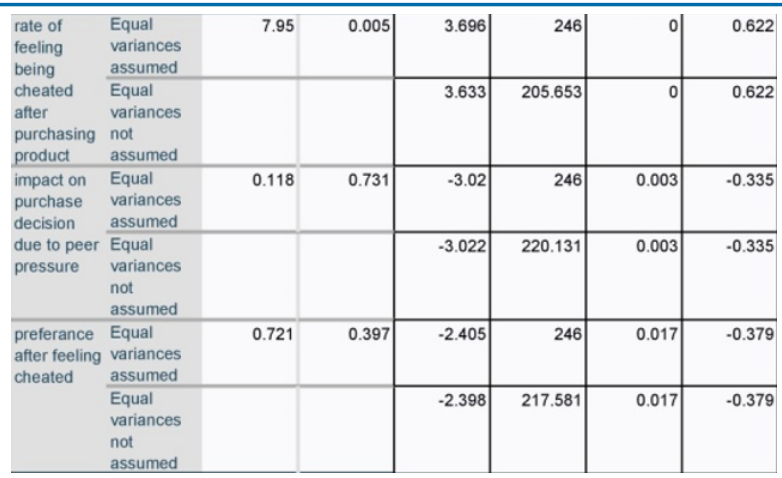

TABLE 4

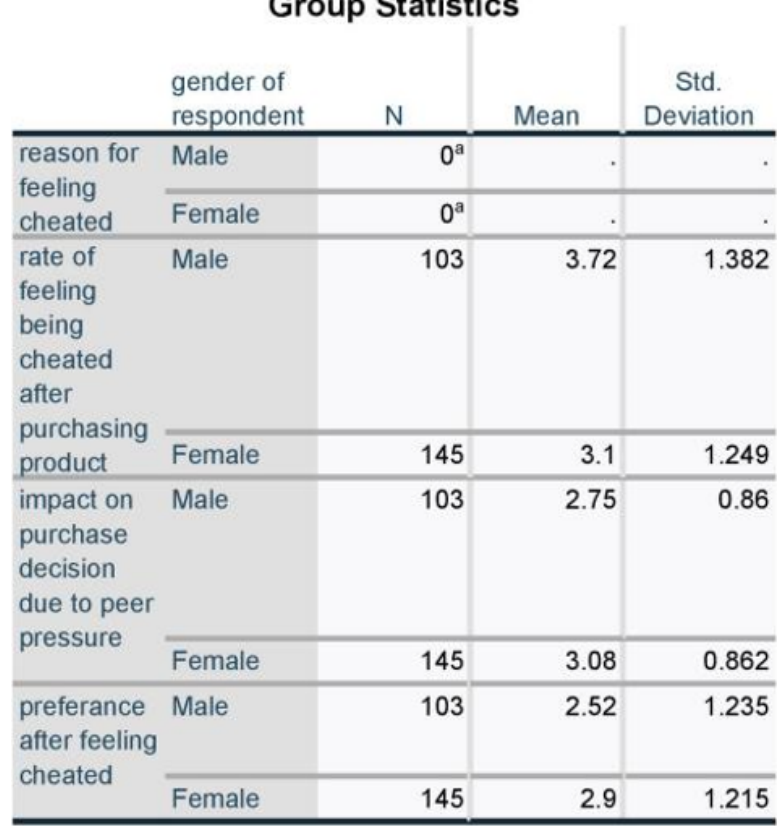

From the above, it is clearly indicated that null hypothesis has been rejected in all the cases. This indicates that there is a significant statistical difference between males and females in brand loyalty towards air filled potato chips packet. For the first case of rate of feeling cheated after product purchase, it can be interpreted that both males and females show a significant difference in mean. Thus, the statistical difference of mean can be summarized in males $=3.72$ \&for females, mean $=3.10$. The higher mean value of males indicates that males clearly feel more cheated than females. Similarly, in second case of impact on purchase decision due to peer pressure, it can be interpreted that both males and females show a significant difference about how they make a purchase decision relating to the product in peer pressure although most of them are hardly influenced by it. Thus, this statistical difference of mean can be summarized in males as $2.75 \&$ for females as 3.08. The higher mean value of females indicates that while making a purchase decision, females experience more peer pressure when compared to males. Next, in case of preference after feeling cheated, it can be interpreted that both males \& females show a significant statistical difference in their response. This result of means can be summarized in males as $2.52 \&$ for females as 2.90 . This higher mean value of females indicates that females still prefer to use the product to an extent than males even after feeling cheated.

\section{FINDINGS \& SUMIMARY}

The study conducted highlights various major points relating to consumer behavior towards air filled potato chips and brand loyalty of consumers. Through this study, it has been found that in the age group of $18-24$ years, people of 20 years age $(30.5 \%)$ consume the highest percentage of potato chips. 
Major brands of potato chips liked by consumers consist of Lays, Uncle Chips, Bingo, Pringles. $83.5 \%$ of them are influenced by flavor, followed by availability and aroma. Interestingly, most of them get to know about more flavors of potato chips by Television Advertisements (49\%) being the highest, followed by information from nearby shops (32.5\%) and social media posts ( $8.5 \%) .69 .5 \%$ of the people agree that more quantity can be added to the product package that they currently use in the same price. $32.5 \%$ of the people fully agree that they feel cheated on the consumption of present product that they purchase due to air filled packet (90\%), followed by high price and other reasons. $35.5 \%$ of the people are likely to recommend their current product. $52 \%$ of the people would like to switch to a brand with better quantity and quality. The reason for not switching earlier are taste $(56 \%)$, followed by availability (18\%), other reasons $(10 \%)$ and price factor (9\%). On a scale of $1-5,33.5 \%$ remain neutral when it comes about the face of the brand they use. Similarly, on a scale of $1-5,34 \%$ of the people remain neutral, when asked about reliability of the current product they use.

Thus, from the study it can be concluded that females consume potato chips more than males. Most of them are influenced by flavor, availability and price most of the time when they purchase potato chips. Also, celebrity endorseme nt has very little impact on most consumers. Same is the case under peer pressure. Interestingly, majority feel cheated due to excess air content in potato chips. Since it is evident from our study that most of them would like to switch their brand with a one which has better quality and quality, potato chips producing companies must take note of this and prepare strategies accordingly to tackle this rising problem in order to retain their customer base and offer a suitable option to consumers.

ACKNOWLEDGEMENT I wish to express my deepest gratitude and thanks to my mentor - Mr Samrat Bharadwaj, Assistant Professor, Digboi College for guiding me in writing this research paper with an encouraging attitude all the time. Without his constant support, writing this would not have been possible. Hence, I wish to place my sincere thanks to him.

\section{REFERENCES}

\section{JOURNALS:}

1. C.Sundarapandi, M.Karthik\& A.K Subrami (2015), "A study on customer satisfaction towards lays chips in Avadi, Chennai", ZENITH International Journal of Business \& Management Research, 5(6), 10-16.

2. Gayatri Joshi \&RuchiraShukla (2012), "Market preference and consumer behaviour regarding packaged snack food products in the selected districts of South Gujarat", Journal of Commerce and Management Research, 2(5), 5062

3. Dr Manish Kumar \& Dr A.K Tiwari (2014), "A study of consumer behavior with reference to Brand Lay's", Pacific Business Review International,6(11), 95101.

4. HadiqaRiaz, Hassaan Ahmed, Dr SaimaAkhter, MudassirHussain(2017), " The Impact of Emotional Branding in Customer Buying Behaviour in Soft Drink Beverage Industry of Pakistan", KASBIT Business Journal, 10, 131-150.

5. Dean Martin C \& Baby Joseph (2013), "Consumer preference in purchase of ready to eat snacks-branded potato chips", Global Journal of Business Management, 7(1), 49-58.

6. N. Ramya\& Dr SA Mohamed Ali (2018), "A study on consumer buying behavior towards Amul products with special reference to Coimbatore city", International Journal of Applied Research, 4 (7), 353-357.

7. E.Thangasamy\& Dr GautamPatikar (2014), "Factors influencing consumer behavior: A case study", Global Journal of Management and Business Research:E-Marketing, 14(5).

8. R. Vijayalakshmi\& Dr. T. R. Gurumoorthy(2019), "Consumer behaviour on purchasing decision of biscuits", International Journal of Scientific Research, 8(1), 403-404.

9. N.Satheesh Kumar, S.P. KaruppasamyPandian\& R. Murali (2013), "An empirical investigation of brand loyalty towards Pepsi- Co Beverages with special reference to Tiruchirapalli district", Research Journal of Economics \& Business Studies, 3 (1), 30-36.

10. SayanMukherjee, SouravChatterjee, Nilanjan Ray (2018), "A comparative study on consumer buying behavior between Parle and Britannia", Remarking An Analisation, 3(8), 67-74.

11. Dr N. Kanimozhi\& Dr S. Karthik (2019), "A study on the brand awareness and consumer satisfaction towards Sunfeast biscuits in Erode district", 9 (5), 231240

\section{CONFERENCE PROCEEDING:}

1. DavinaMadhaviChinnapen- Sathan, VanishaOogarah- Hanuman

|www.worldwidejournals.com
\&RoomaRoshneeRamsaran- Fowdar(2012), " Analysing the Impact of Advertising in the Soft Drink market of Mauritius: The Case Study of Coca -Cola", ISBM International Symposium, 160-17. 